\title{
Animal Cultures, Subjectivity, and Knowledge: Symmetrical Reflections beyond the Great Divide ${ }^{1}$
}

\author{
Richie Nimmo \\ University of Manchester, \\ Richie.Nimmo@manchester.ac.uk
}

\begin{abstract}
This article reflects upon the implications for sociology of the steady accumulation of evidence in the sciences of animal behavior pointing to the existence of culture among nonhuman animals. With a particular focus on primatology, it explores how these developments challenge the notions of "culture" that continue to inform the study of human social life. The article argues that this growing challenge to the assumption of human uniqueness that has historically provided the core rationale for sociology cannot be ignored. The paper thus contributes to the overdue work of articulating a constructive response by tracing the issues involved in the encounter between these knowledges. Theoretical currents from science studies and actor-network theory are drawn upon in order to propose a reflexive and symmetrical realignment of this encounter, with significant implications for our understandings of human and animal being and subjectivity.
\end{abstract}

\section{Keywords}

culture, knowledge, primatology, reflexivity, sociology, subjectivity, symmetry

\section{Introduction}

The empirical evidence for the existence of culture among nonhuman primates and various other nonhuman animals has been accumulating for several decades. Throughout the multiple, overlapping fields that make up the scientific study of animal behavior, there is an increasingly widespread use of the concept of "culture," and a growing acknowledgment that various nonhuman animals must be considered "cultural" creatures (Boesch, 2003; Whiten, 2000; McGrew, 1998, 2003; Wrangham, De Waal, Heltne, \& McGrew, 1994). But these developments have hitherto been largely ignored by the social sciences, and by sociology in particular, which for the most part has proceeded as though the emergence of "culture" among nonhumans has no implications for sociological understandings of human life and behavior. ${ }^{2}$ 
This disengagement becomes increasingly unsustainable with the mounting weight of empirical evidence. Moreover, it need hardly be said that an outward-looking sociology would involve open and reflexive engagement with significant developments in the natural sciences, even-indeed, especiallywhere they may challenge certain of its foundational assumptions. But what the modality of such engagement should properly be is a more difficult issue.

At the heart of the encounter between these formations lies the enduring question of how our knowledge of other animals is constituted: what is the nature and status of such knowledge, what are its limits, if any, and what are the implications for how we understand animal being and subjectivity? This intersection between questions of epistemology and "the question of the animal" has been recognized by those in human-animal studies who have stressed the performativity of knowing animals in particular ways. Specific forms of animal knowledge and their associated languages enact and shape particular ways of seeing animals and hence particular kinds of human-animal relationship, and indeed vice-versa (Irvine, 2004; Crist, 2000; Arluke \& Sanders, 1993). A key concern in this article is to follow through the implications of this for the encounter between sociology and primatology-an encounter made unavoidable by the latter's turn to culture. This will involve examining how certain conceptions of humanity and animality are not just addressed explicitly in aspects of the content of these knowledges but are embedded in their very epistemologies.

Bound up with questions of knowledge are questions of phenomenal experience, intersubjectivity, and communication: how do different beings experience the world and how much of this can be meaningfully translated across species boundaries? Human-animal studies scholars have increasingly criticized the tendency to treat animals merely as bearers of human social relations or culture and have advocated a greater attentiveness to the animal itself or the animal's perspective (Shapiro \& Copeland, 2005; Fudge, 2002; Arluke \& Sanders, 1996). Drawing from feminist and postcolonial sensibilities and a critical wariness of speaking for the Other, this line of thought seems implicitly to lament the absence of a transparent interspecies dialogue in which the animal could speak for itself, unmediated, and hence shape its own existential testimony free from the distortions of human discourse. With the problem thus defined, science can then seem to proffer a means to reveal what is otherwise hidden. As Shapiro and DeMello (2010) recently put it, "Increasingly, the sophisticated technology of the hard sciences allows us to 'see' animal minds, animals thinking and acting."

But if critical and relational understandings of the constitution of modern knowledge that have emerged from currents in science studies and actor-network 
theory are taken seriously (Michael, 2000; Latour, 1993, 2004), then it is the modern ontological separation of the human from the nonhuman and the corresponding division between the natural and the human sciences, rather than any communicative, corporeal, or existential frontier that is most instrumental in creating the boundary between species. If this is so, then in order to grasp the animal's perspective, or, better, in order to dissolve the epistemic gulf that seems to separate the human from the animal, we must be prepared to cross the "great divide" of modern knowledge. This article explores the ways in which the emergence of nonhuman animal "culture" in the sciences both is and is not an instance of such boundary crossing.

\section{Nonhuman Cultures}

So, what did the primatologists find when they looked at their subjects? Inevitably, and, for some humans, terrifyingly, they found one of the things that was assumed to be the domain of the human. They found, in fact, culture. (Fudge, 2002, p. 132)

A large and growing body of empirical research attests to the central role of culture in nonhuman animal lives (De Waal \& Tyack, 2003). This has emerged from across a number of overlapping disciplines and fields, from behavioral biology to cognitive ethology and from comparative psychology to field primatology. ${ }^{3}$ Each has its own distinctive concerns, assumptions, and methodologies; hence, what each means by "culture" is inevitably slightly different. What is common to these uses of "culture," though, is the signification of a certain distance and autonomy from nature; whatever nature is conceived to be, culture is other than nature. Given the current primacy of genetic conceptions of nature, the most basic and persistent working definition of culture in reference to nonhuman animals is "behaviour that has been passed from one generation to another by non-genetic means" (McFarland, 2006, p. 45; cf. De Waal, 2001). The various uses of "culture" across the sciences of animal behavior are united in seeking to operationalize this core idea, albeit in different ways.

Similar developments have been taking place across behavioral studies of a diverse range of species, from dolphins to birds and even insects, but they are at their most advanced in the study of the great apes, and, above all, chimpanzees. As primatologists Christophe Boesch and Michael Tomasello (1998) explain:

To a degree unknown in any other species of nonhuman animal, primate or otherwise, different populations of chimpanzees seem to have their own unique behavioural 
repertoires, including such things as food preferences, tool use, gestural signals, and other behaviours, and these group differences often persist across generations.... From the biological point of view, there is no question that much of chimpanzee behaviour is culturally transmitted in the sense that individuals consistently acquire behaviours specific to their population in ways that do not depend directly on genetic transmission or upon obvious ecological conditions. (p. 592)

This has led to the emergence of "cultural primatology" as "a subset of investigations interested in the culture (as opposed to the anatomy, ecology, genetics, or physiology) of nonhuman primates" (McGrew, 2003, p. 420), which is at the forefront of a wider turn to culture across the sciences of animal behavior. The implications of these developments for sociology are profound, for the assumption that culture is an exclusive and defining property of human beings has furnished sociology with its core rationale and disciplinary identity, and provided the basis for its demarcation vis-à-vis the natural sciences (Nimmo, 2011; Sanders, 2006). Almost every sociology textbook still begins by asserting the separateness of human society from the nonhuman world and the uniquely cultural nature of human beings. It is unsurprising then that there has been a marked lack of sociological engagement with animal cultures, if the very viability of the idea of sociology appears to be at stake. Yet the possible responses seem stark. Hitherto the main response has been simply to ignore the issue, or to continue to insist upon the human uniqueness of culture in denial of the accumulating evidence suggesting otherwise. But this means redefining culture in increasingly anthropocentric terms and continually shifting ground to new criteria of inclusion whenever the previous bastion of human unicity is breached, with each defensive shift of criteria less convincing than the last. As cognitive ethologist Marc Bekoff (2004) points out:

\footnotetext{
When we carefully parse the criteria that have been frequently used to separate "us" from "them"- - tool use, language, art, culture, feelings, consciousness-we find ourselves on thin ice, for none shows that we represent some sort of evolutionary discontinuity. (p. xi)
}

The opposing possibility is to accept the reality of nonhuman animal culture along with the consequences - the unexceptional nature of human beings and the "animality" of the human. This is often regarded as the necessary basis of nonanthropocentric thought, but it remains highly problematic, because its corollary within the existing structure of knowledge is the subsumption of the social sciences under an overarching natural science of human and nonhuman behavior. This was the logic of the project of sociobiology, and there are those who still advocate something along these lines, and not just from within the 
natural sciences (Corbey, 2005; Fox, 1989; Wilson, 1975). Quite apart from its political implications, for all the rich interpretive, hermeneutic, and historical work on the complexities of human social action to be either abandoned or hollowed out and reattached to a positivistic model, whether genetic, cognitive, or neuroscientific in character, would arguably be a huge loss and a tremendous regression in understandings of human behavior. But support for such a reductionist position may well arise from frustration at what appears to be the only alternative, namely continuing insularity, intransigence, and pseudo-theological insistence upon human uniqueness and the autonomy of human culture. For those who regard such human exceptionalism not just as misconceived but as central to the mode of life that has brought us to the brink of ecological catastrophe, the relative dangers of the biological and social reductionisms apparently on offer may seem less than clear-cut.

\section{The Great Divide}

Beneath the tension between sociology and scientific studies of animal "culture" lies an encounter between distinct cosmologies or worldviews. This is clearest in the case of social science: the view that human beings are distinguished from the nonhuman world by the possession of culture is not just an empirical claim but is ultimately cosmological and concerns the position of humanity in the world. It asserts the irreducibility of the human existence to any conception of nature, biology, mechanistic causality or determinism. This is fundamentally a vision of human existential freedom, and much of social science epistemology can be understood as a systematic working-through of the consequences of this freedom for how human beings and human social action should properly be understood (Plumwood, 1993). The master narrative is of one of self-authorship or self-creation, entailing sociopolitical possibility and responsibility, and temporally oriented toward future social change.

The scientific study of culture among nonhuman primates may look more strictly empirical, but it is really no less cosmological than its social scientific counterpart. In this case it is not human autonomy that is being affirmed but human continuity with nature and with other species. The master narrative here is evolution rather than existential freedom; what is valorized is selfknowledge rather than socio-political responsibility; and the temporal orientation is toward the past rather than the future-typically toward some notion of human origins, or the "evolutionary roots" of human culture.

These contrasting cosmologies are intricately tied to different ontological visions of "culture": on the one hand there is the foundational idea underlying the interpretive, phenomenological, and humanist traditions in social science, 
which understand culture as intersubjectivity. In an intellectual lineage strongly influenced by the epistemology of Kant but traceable most directly to the methodological stance of sociologist Max Weber (1964; 1968), culture is held to consist of the webs of situated meanings that arise in social interaction between conscious and reflexive subjects. Crucially, these intersubjective meanings are held to shape social action, thereby undermining causal explanations of human behavior (Winch, 2007). For interpretive sociology, subjects act in accordance with the ways in which they themselves understand and define situations; it follows that culture and social action are not in any way mechanistic but consist of meaningful actions (Weber, 1964). These in turn are thoroughly context- and situation-dependent and can therefore only be understood in terms of a first-person ontology - that is, in terms of the selfunderstandings of cultural subjects. Any third-person, externalist, or objectivist view of culture is therefore regarded as a reification-the making into a "thing" of something quintessentially un-thinglike. Subjects are socially constituted within webs of intersubjective meanings, just as they simultaneously weave these webs of meaning through their reflexive, purposive, and meaningful actions.

The sciences of animal behavior present a somewhat more complex and contradictory picture. On the one hand, their most basic definition of culture, as we have seen, is that culture is not nature, which is currently construed to mean behavior that is transmitted by nongenetic means. And yet culture is simultaneously inscribed as part of nature by the core epistemology of this approach; insofar as it proposes that culture can be studied scientifically, cultural primatology represents an extension of modern scientific epistemology to culture. But science fundamentally proceeds by inscribing the products of its knowledge as objects, knowable by a suitably detached observer (Birke, 1994; Haraway, 1990). Thus by attempting to produce objective knowledge of culture, cultural primatology is effectively inscribing culture as an object, in the sense of culture being part of an object-world, continuous with nature and amenable to being known in an objective scientific manner. This means that in terms of the epistemic architecture being employed, there is no necessary connection between culture and the conscious "inner" lives of subjects, and indeed no acknowledgment of the subjectivity of animals is required by this approach (Crist, 2000); cultural behavior is not seen as necessarily driven by the phenomenal understandings and intentions of subjects but by causal mechanisms of one kind or another.

This is consistent with the technical definitions of culture characteristic of much cognitive ethology and comparative primate psychology, for which "culture" denotes a particular kind of nongenetic information transfer or 
learning mechanism, or a specific sort of cognitive process, depending upon the subdiscipline in question (Boesch \& Tomasello, 1998). Thus, animals are seen as bearers of an agency that is overdetermined by evolutionary imperatives and located elsewhere, whether in the genes, in hormonal or biological drives, in neurobiology-in short, anywhere in the brain-body of the animal as a biological object but never in the whole animal itself as a conscious subject (Crist, 2000). The contrast with the interpretive and intersubjective conception of culture could not be sharper.

The dilemma that arises from the incommensurability of these cosmologies and their associated conceptions of culture is that the hypothetical triumph of either would lead to a deeply flawed approach to humans and animals alike. The ostensibly nonanthropocentric option is to posit a natural science of human and animal sociality rooted in an essentially objectivist view of culture. The appeal of this is that it avoids making a speciesist distinction between humans and other animals, instead positing human beings as firmly part of the natural world. But this sort of project has been the subject of trenchant criticism in the social sciences, most notably from feminist and science studies scholars, who have shown that natural science operating as social science in this way tends to become a vehicle for the naturalization of power relations in human society, most notably around gender, but also around social relations of race, class, and hierarchy (Hubbard, 1990; Keller, 1985). From this perspective, as Donna Haraway (1984) succinctly puts it, "primatology is politics by other means" (p. 489).

This is not just of historical relevance. In contemporary evolutionary psychology, for example, distinctly ideological visions of social organization are routinely given the hard sheen of scientific objectivity before being energetically popularized (Jackson \& Rees, 2007). The main concern here, however, is not with an ideology-critique of such tendencies, but with showing how the objectivist model depends upon being systematically unreflexive when it comes to the relationship between its object of knowledge and its own knowledge-practices, and in a way that is particularly problematic when it comes to studying culture.

\section{Culture as Nature: Positivism in Primatology}

A relatively young field, emerging in the early 20th century and becoming a full-fledged science only in the 1960s and '70s, primatology's developmental trajectory has been complex. Long regarded by the more established sciences as a borderline field of questionable scientific status, due in significant part to 
the uniquely liminal role of primates within modern Western cosmology (Corbey, 2005; Haraway, 1990), an important dynamic in primatology's maturation has been its struggle for recognition as a rigorous and objective science. Notwithstanding the work of some early pioneers of fieldwork observation in the interwar years and the earlier less-systematized observations of explorers and naturalists (Rees, 2006; Mitchell, 1999), the initial period of institutionalization of primatology in the 1950s centered upon laboratory studies of captive populations, mainly of chimpanzees, utilizing the experimental methodologies most associated with the natural sciences. Fieldwork and observational methods were at this time seen as a form of natural history rather than "hard" science, given their reliance on observation and classification, rather than controlled experiments producing testable facts, and were thus treated as at best supplemental to the more reliable knowledge that could be produced under the controlled conditions of the laboratory.

It would be an oversimplification to claim that there has been a neat inversion of this epistemic hierarchy, but during the last forty years the perceived advantages of laboratory experiments in terms of control, reliability, and replicability, have increasingly been weighed against numerous problems that have come to be associated with captive studies (Rees, 2006; Haraway, 1990). Chief among these is the recognition that primates tend to behave differently in captive conditions, so that what is being studied is no longer really "natural," but is to some extent produced by the laboratory itself. This has led to a gradual valorization of the role of fieldwork and observational methods, and a concerted effort to render these more objective and reliable, notably through the use of highly standardized observational criteria from which almost all need for interpretation on the part of the observer has been stripped out (Rees, 2006). Meanwhile, laboratory studies—-though still importanthave in many cases come to play a more complementary role, being used to generate hypotheses or to subject the data emerging from field studies to controlled tests.

Understood reflexively, this gradual revaluation of the relationship between captive studies and field studies is in itself an oblique acknowledgment of the problems of studying culture as an object. The initial project of studying primate behavior in laboratories was based upon the naïve idea that, as part of "nature," primates and their behavior could simply be relocated to these artificial spaces of observation where they would go on manifesting their nature as before (Rees, 2006). But the primates soon demonstrated that their behavior was intimately tied to place and context, and sensitively calibrated to an ecological and social-relational milieu. In effect, the laboratory, far from purifying the nonhuman object of any distortive relation with the knowing human 
subject, was instead serving to expose the inescapable interrelationality of primates and humans within a common social and ontological space.

As the pure-object status of primate behavior could not be assured in the laboratory, it was deemed necessary to rely more heavily upon studying these animals in their natural environments. But given the already liminal status of primatology, the prospects of scientific recognition for a field primatology viewed as a branch of natural history were dim. Hence the history of Western field primatology and the development of its methods can be understood as an ongoing effort to establish the scientific credentials of this alternative to laboratory studies. This has involved the progressive refinement of techniques for rendering lived encounters between subjects in terms of objective knowledge, in a sort of epistemological alchemy. But these purification techniques are constantly in tension with the affective subjectivity of both groups of primates, that is, the humans and the nonhumans, the observers and the observed on both sides. For example, Amanda Rees (2007) has documented how in their everyday working practices field primatologists tend intuitively to locate themselves in a common existential and relational space with their primate subjects, to whom they routinely attribute many of the characteristics of "culture" understood as lived intersubjectivity, individuality, embodied selfhood, and self-consciousness. This is integral to the everyday practice of field primatology, and yet such "anthropomorphism" and "anecdote" are meticulously avoided in research publications in the name of properly rigorous and objective science, typically being expressed only belatedly in popularizations and personal accounts. In this way the affective and relational experience of intersubjectivity in field primatology, though fundamental to the practice of field observation, is systematically purified out of the formal scientific knowledge itself.

Another example of the tensions intrinsic to the transformation of subjects into objects in scientific field primatology is apparent in the role of habituation. In the earliest field studies, the key problem of the laboratory basically reproduced itself; as soon as the primates became aware of the presence of human observers, their behavior changed markedly. The method for overcoming this was established only after considerable trial and error. It consists of maintaining the constant or frequent presence of observers so that the primates become habituated to the proximity of humans and thus return to their "natural" behavior (Williamson \& Feistner, 2011; Rees, 2006). This has become central to the practice of field primatology as a precondition for the viability of a field site, and yet it receives only cursory attention in the scientific literature, where it tends to be treated as a prior condition of knowledge, rather than an active part of knowledge production. This is characteristic of 
modern science in rendering invisible the social conditions of its knowledge, so that the resultant object appears to be speaking for itself, unmediated by subjects or subject relations (Birke, 1995; Hubbard, 1990).

In this way, habituation is inscribed as an absence, more specifically an absence of the relations with humans deemed to compromise captive studies. And yet it depends precisely upon the presence of a certain kind of intersubjective relation between observers and observed, which is actively established and maintained; it relies upon the primates perceiving the humans in a certain way. Thus, far from being a technique for securing the "natural," authentic object status of primate cultures by ensuring the absence of human-animal intersubjectivity, habituation is more accurately seen as itself an intersubjective social relationship. Recognition of this dramatically transforms the ontological status of the knowledge produced, the authenticity of which is no longer predicated upon the separation of knowing subjects and known objects, but upon the careful establishment of certain kinds of reciprocal relations of trust between subjects: the human observers get to know the nonhuman primates in proportion to the extent that the primates get to know the humans.

The methodological trajectory of primatology, then, in its gradual shift of emphasis from laboratory to field studies, as well as in the evolution of field methods themselves, can be understood in terms of a long-term pursuit of objectivity. ${ }^{4}$ And yet the tensions that have centrally driven these developments, which remain internal to the practice of field primatology, manifest an inverse trajectory, with the progressive eruption of subjects and intersubjective relations into the apparatus of objective knowledge production. Thus, primate "culture" has consistently refused to behave as though it were a set of objectrelations, perpetually leaking through as quasi-subjective or intersubjective relations, compelling primatology to employ increasingly stringent and standardized methods in striving for scientific status. But there is always an excess, an Other that haunts scientific accounts of culture, which cannot be quite purified away because it is inscribed by the object itself. This Other is the subject and intersubjectivity, the raison d'être of the humanities and social sciences.

\section{Humanism beyond Humanity}

Turning to the model of culture as intersubjectivity, the most immediate obstacle to its use with reference to nonhuman animal cultures is its foundational anthropocentrism; as conventionally used in the social sciences, this model categorically excludes nonhumans from the sphere of culture. The 
interpretive and interactionist tradition in sociology defined itself by asserting a rigid human/animal divide. In Max Weber's $(1964,1968)$ work, and even more clearly in the work of George Herbert Mead (1967) and Alfred Schutz (1967), who laid the groundwork for symbolic interactionist and phenomenological sociology, there was a sharp and recurrent distinction between "meaningful social action" and "mere behaviour," which was mapped directly onto the human/animal divide (Crist, 2000, p. 210). Symbolic communication and complex language were considered essential to the possession of a "self" and hence to meaningful social interaction with others (Sanders, 2006). Animals were deemed to lack language, and without language there could be no webs of meaning, hence no culture and no cultural subjects.

Fortunately, the exclusion of nonhuman animals characteristic of this model has been comprehensively challenged over the last fifteen years by sociologists of human-animal interaction, who have reworked the approach around much broader notions of meaningful communication as fundamentally embodied, corporeal and multisensory, rather than narrowly symbolic or linguistic (Irvine, 2004; Alger \& Alger, 2003; Myers, 2003; Arluke \& Sanders, 1996). In this way animals have been theoretically repositioned as active participants in a coproduced and intersubjective culture, rather than categorically excluded from an exclusively human cultural world. This builds upon recognition of the fact that many nonhuman animals are deeply involved in a diverse range of human social activities, social relations, and associated systems of meaning, and as such are already entangled in society and culture (Bryant, 1979). But challenging the exclusion of animals from the domain of culture also has profound implications for conceptions of human and animal being, subjectivity and experience, since it challenges the philosophical skepticism that underpins scientific and objectivist approaches as well as traditional humanism.

Traceable to the mind/body dualism of Descartes, skepticism locates animal subjectivity or "mind" somewhere "inside" the animal, in some private ontological space of inaccessible interiority (Crist, 2000, p. 216). At the same time, the animal's "external" bodily behavior is dislocated from this and thus deemed bereft of meaning - it is merely mechanical, any meaning lying hidden within. The problem then becomes the intractable one of how to access the animal's inner "mental" experience, without which all inferences concerning the meaning of its behavior can be dismissed as mere projections of human meaning onto the animal. In Descartes's own words, "We base our judgement solely on the resemblance between some exterior actions of animals and our own; but this is not at all a sufficient basis to prove that there is any resemblance between the corresponding interior actions" (cited in Crist, 2000, 
p. 216). Hence this dualist framework ensures that the subjectivity of the animal, rendered intangible and unobservable, becomes the subject of skeptical doubt, which in turn invites and legitimizes scientific studies of animal behavior that can claim to mobilize special methods to reveal the "inner truth" of the animal.

The extension of the interactionist approach to animals challenges these interconnected tenets of dualism and skepticism by suggesting instead that animal "mind," or the meaning of animal behavior, is not hidden somewhere inside the animal but is coconstructed relationally in interspecies interaction. Animal subjectivity, in this view, is constitutively present in interaction, "performed" in behavior, and open to view as embodied consciousness. In this perspective, the problem of animal minds is not solved as such, but rather disappears as a false problem rooted in an inappropriate Cartesian skepticism; we already understand animal subjectivities as well as we could reasonably ask because they are part of the culture in which our own subjectivities are enacted. Thus the problem is not that we cannot see inside the animal and perceive the world from "the animal's point of view," but simply that the categories of our thought and perception render us blind to what is readily apparent.

This proffers a way to dissolve the human/animal boundary and to bring humans and nonhuman animals within the same ontological, existential, and ethical domain, without having to posit a biologically reductionist view of human beings or a behaviorist view of culture. In essence it incorporates animals into culture within a broadly humanist worldview, rather than incorporating humans into nature within the scientific worldview. But does this effectively obviate the need for scientific studies of animal culture? The answer is to be found in the range of empirical studies informed by this sort of approach, for it is notable that such work has overwhelmingly focused upon companion animals and work environments in which domesticated animals play a key role (Irvine, 2004; Alger \& Alger, 2003; Sanders 1999). The animals in question are very much incorporated into human social environments and human social relations and systems of meaning; indeed, domestication means that a species is "enfolded into the social structure of the human community" (Clutton-Brock, 1995, p. 15). The same clearly cannot be said of primates in their natural environments or indeed of "wild" animals in general.

While the rapid expansion of human societies all over the world means that there are now very few groups of primates wholly untouched by the effects of human development, it would be implausible to maintain that the cultures of free living primates are therefore indistinguishable from their enmeshment in human socio-cultural milieus, as one might more reasonably argue of species with a long history of close coevolution with humans, such as dogs and cats 
(Haraway, 2003; Clutton-Brock, 1995). Hence, far from scientific studies of primates being rendered redundant:

Without primatology, in order to speak of apes and monkeys, we would have to rely on a few anecdotes brought back by missionaries and explorers; we would have no data, no comparative basis, no more than the shabby representations of wilderness and savagery with which Western culture has equipped us from the beginning. (Latour, 2000, p. 359)

This suggests that the anthropocentrism of the intersubjective framework is not entirely extirpated even where the domain of culture is extended beyond human beings. The problem is that animals are rendered subjects here only insofar as they are incorporated into structures of meaningful interaction shaped by human social activities; they are cultural beings only insofar as human beings confer such a status upon them-hence the focus upon domesticated animals, which lend themselves to this approach.

Such objections underline the problems inherent in extending humancentered perspectives in order to incorporate animals into a domain of "culture" that is still conceived anthropocentrically. As Cary Wolfe has argued, "just because we are studying nonhuman animals does not mean that we are not continuing to be humanist - and, therefore, by definition, anthropocentric" (Wolfe, 2009, p. 568). If animals are indeed cultural creatures, then in certain contexts their cultures are certainly overlapping and interpenetrative with our own, but in others they will be more or less autonomous. It is therefore complacent - and indeed anthropocentric - to deny animal otherness by suggesting that animal cultures must be relatively transparent to human beings. Indeed, if culture is "a whole way of life" (Williams, 1983), then animal cultures must be recognized as being embedded in the unique speciesbeings of particular forms of life, which are inseparable from particular kinds of brains and bodies, and which human beings therefore can never entirely share (Nagel, 1974). But reasserting skepticism and hence the case for science against interpretivism on this basis would merely return us to the aporias of the unreflexive objectivity previously discussed. A more constructive and symmetrical way forward is to acknowledge that neither the scientific nor the interpretative model of animal cultures can ever be entirely adequate, and thus to explore other ways of thinking about human and animal being.

\section{Toward a Symmetrical Knowledge}

It should by now be clear that the contradictions between the contrasting conceptions of culture embedded in cultural primatology and interpretive 
sociology respectively, are just so many oscillations between subject and object or culture and nature within the structure of modern knowledge defined by that dualism. Neither can ever be wholly triumphant, as each presupposes the other even while suppressing and denying it; the more objectively the object appears, the more subjectively the subject arises, and indeed vice versa. But new understandings of the constitution of modern knowledge emergent from currents in science studies and actor-network theory provide a way beyond this impasse - not by proposing some sort of dialectical synthesis, but by dissolving "subject" and "object" into assemblages of hybrid and entangled relations within a materially heterogeneous collective. ${ }^{5}$ This nonmodern way of seeing enables not so much a solution to the tension between primatology and sociology as a symmetrical realignment of their terms of engagement, with an attendant reconceptualization of humans and animals.

At the core of science studies is a commitment to treat scientific knowledge as socially embedded knowledge produced within social practices or "knowledge-practices" (Latour \& Woolgar, 1986). Thus, science is no longer to be seen as inhabiting a domain of truth and objectivity somehow transcending the "social," but rather science is social activity and scientific knowledge is socially constructed knowledge. This is a fundamental challenge to the entrenched epistemological division of labor according to which the natural sciences are in the business of discovering universal and objective truths and are therefore assumed to be exempt from the kinds of social, cultural, and ideological processes examined by the social sciences. Early work in this vein was characterized by close ethnographic studies of laboratory practice, highlighting the disparity between the self-presentation of scientific knowledge as objective, universal, and detached, and its far messier reality, in which scientific knowledge-practices involved all kinds of contingencies and ad hoc arrangements. Such practices were also found to weave together subjects and objects, or humans and nonhumans, so closely in hybrid networks as to render their analytical separation nonsensical.

This was not an ideology-critique of science or a claim that science was "merely" socially constructed, but rather an attempt to explain the peculiar power of modern science. For science studies, this is ultimately attributed to the way in which science has managed to enroll heterogeneous objects and materials into its social-epistemic networks in such a way as to make its knowledge-claims remarkably concrete, dense, and durable. A defining move for actor-network theory was to take this view of scientific knowledge as something produced within social practices and apply it symmetrically to all knowledge-practices, including those of the social sciences. Recognizing the asymmetry involved in treating science and nature as socially produced while 
still assuming that the domain of society and culture was simply "real," ANT posits the radically symmetrical argument that "culture" or "society" are similarly produced within practices, and that these practices are not themselves a priori social or cultural, but heterogeneous, for they include the objects of scientific knowledge, which is to say, "nature" and nonhumans:

If nature and epistemology are not made up of transhistoric entities, then neither are history and sociology_unless one adopts some authors' asymmetrical posture and agrees to be simultaneously constructivist where nature is concerned and realist where society is concerned! (Latour, 1993, p. 27)

In this way ANT goes beyond the asymmetric logic of social construction by showing how subject and object, culture and nature, human and nonhuman, are not separate sorts of entities at all but are actually mutually constitutive in their intermediation within the ontological structure of modern knowledge.

Reconceptualizing the turn to culture in the sciences of animal behavior along these lines fundamentally transforms the nature of its encounter with social science. With the dissolution of a monolithic "nature" into heterogeneous assemblage and intermediation, the specter of a deterministic natural science of human and animal behavior recedes. Such a reductive project is shown to be untenable, since it depends upon perpetually suppressing its own reflexive contradictions as well as its relational conditions of possibility. In short, culture cannot be subsumed under nature without simultaneously changing the meaning of "nature" in such a way as to render such objectivism incoherent. Thus, rather than leading inexorably to reductive accounts of human society, the acknowledgment of animals as cultural beings could well help to challenge mechanistic and reductive views of human nature by showing that even nonhuman animals are not biological automata. This is not because animals are autonomous of biology, but because biology itself is not autonomous, being embedded within a wider ensemble of heterogeneous relations.

The interpretative model of culture is also transformed beyond recognition by this symmetrical realignment. The notion of culture that emerges still concerns the relations between subjects, but far from being irreducible, these subjects are always already entangled with and mediated by quasi-objects of all kinds, so that there is no subject "in itself." Thus the intersubjective meanings privileged in humanist approaches emerge from heterogeneous lifeworlds in which everything human is inseparable from multiple nonhumans, and where there is no moment of pure humanity. It is not so much a matter of extending the sphere of culture and subjectivity to encompass animals, then, as of deconstructing the anthropocentric categories of "culture" and the 
"subject" altogether, albeit without collapsing them back into "nature," biology, or objectivity - their counterparts within modern dualist ontology. Instead, the emergent cosmology must be one in which beings of diverse kinds coexist within a relational collective that is neither culture nor nature.

\section{Conclusion}

Detached from the fetters of scientific epistemology and relocated within a symmetrical and relational framework, cultural primatology appears broadly continuous with the forms of intersubjective interpretivism central to sociological approaches to animal cultures, rather than an entirely different order of "objective" knowledge. But far from this diminishing its status, it is then that its true significance emerges: no longer another asymmetric modernist science studying object-nature, cultural primatology as an ensemble of knowledge-practices turns out to be engaged in the quintessentially posthumanist project of assembling a means properly to acknowledge animal being in all its difference and alterity without recourse to either anthropocentrism or anthropomorphism. Its value consists precisely in the construction-within the simultaneously epistemic and material networks it assembles-of ways to inscribe animal alterity and specificity, refusing to brush these aside in the name of an assumed interspecies transparency that erases difference, while simultaneously refusing to endorse skepticism by rendering animal being unknowable.

Though still obscured and distorted in actually-existing primatology by the restrictions of scientific epistemology, this modest and pragmatic approach has a radical kernel, because it represents an embryonic break with the ontological framework that underpins both humanism and positivism. It serves as a powerful reminder that the search for the animal's point of view-a recurring and seductive idea not only for natural scientists but sometimes for interpretivists in sociology and human-animal studies - is ultimately a chimera; an unwitting regress into Cartesian skepticism. Knowing others-human or nonhuman - is inescapably an iterative process of interpretation in mediated and embodied interaction, rather than a matter of somehow gaining objective knowledge of what is inside the mind of the other. Hence, making animal "minds" the central problem inadvertently reinscribes the internal/external dichotomy so intricately connected with the human/animal dualism it wants to deconstruct. A more symmetrical sensibility would acknowledge the inescapably mediated nature of subjectivity, the relational and situated nature of 
all knowledge, including self-knowledge, and hence the difficulty—but not the impossibility - of knowing others, human and nonhuman alike. Thus freed from the self-imposed myopias of skepticism, dualism, and anthropomorphism, animal subjectivity —or, better, animal being — is every bit as palpable as that of other human beings, but need no longer be defined or measured either by its distance from biological necessity or by its similarity or intelligibility to human beings.

Such a worldview calls for a hybrid knowledge, unfettered by the "great divide" that underpins the demarcation of modern disciplines, which can draw upon the technical repertoires of science and the epistemological reflexivity of the social sciences and humanities simultaneously, symmetrically, and without contradiction. Far from representing an existential threat to the social sciences, the emergence of animal culture in the natural sciences offers an unprecedented opportunity for the sort of disciplinary rapprochement and boundary crossing that is needed to begin to assemble this kind of knowledge.

\section{Notes}

1. I am grateful to the Animals \& Society Institute and to Wesleyan University for enabling me to research and write this article while participating in the Human-Animal Studies Fellowship 2011. I am also indebted to the anonymous reviewers for their astute comments, and to the editors of this special issue for their guidance.

2. Although I believe that my argument applies broadly to much of social science, my focus here is mainly on sociology, since the analysis would need to be nuanced in various ways for other disciplines, which would be beyond the scope of this paper. Anthropology, for example, has proved somewhat more amenable to engaging with the implications of animal cultures.

3. For convenience and brevity, I will often refer to this assemblage as "cultural primatology," without wanting to suggest that the turn to culture across the sciences of animal behavior is either reducible or exclusive to this subfield, or indeed that this subfield is itself unitary or exclusive.

4. Of course there is not one primatology but many, and this heuristic picture is too neat to capture the dynamics of even Western primatology in all its complexity (cf. Strum \& Fedigan, 2000). Nevertheless it does capture the overall broad pattern of epistemic and methodological change.

5. Although I focus on science studies and ANT here, several other interesting theoretical and critical currents offer potentially fruitful and complementary new ways to think about human and animal being, including posthumanism and the new relational materialism (cf. Coole $\&$ Frost, 2010; Wolfe, 2010; Haraway, 2007). 


\section{References}

Alger, J., \& Alger, S. (2003). Cat culture: The social world of a cat shelter. Philadelphia: Temple University Press.

Arluke, A., \& Sanders, C. (1993). Understanding dogs: Caretakers' attributions of mindedness in canine-human relationships. Journal of Contemporary Ethnography, 22(2), 205-226.

- (1996). Regarding animals. Philadelphia: Temple University Press.

Bekoff, M. (2004). Foreword: To know them is to be them. In L. Irvine (2004), Ifyou tame me: Understanding our connections with animals (pp. vii-xii). Philadelphia: Temple University Press.

Birke, L. (1994). Feminism, animals and science: The naming of the shrew. Maidenhead: Open University Press.

- (1995). Exploring the boundaries: Feminism, animals and science. In C. Adams \& J. Donovan (Eds.). Animals and women: Feminist theoretical explorations (pp. 32-54). Durham: Duke University Press.

Boesch, C. (2003). Is culture a golden barrier between human and chimpanzee? Evolutionary Anthropology, 12(2), 82-91.

Boesch, C., \& Tomasello, M. (1998). Chimpanzee and human cultures. Current Anthropology, 39(5), 591-614.

Bryant, C. (1979). The zoological connection: Animal-related human behaviour. Social Forces, 58(2), 399-421.

Clutton-Brock, J. (1995). Origins of the dog: Domestication and early history. In J. Serpell (Ed.). The domestic dog: Its evolution, behaviour and interactions with people (pp. 8-20). Cambridge, United Kingdom: Cambridge University Press.

Coole, D., \& Frost, S. (2010). New materialisms: Ontology, agency, and politics. Durham: Duke University Press.

Corbey, R. (2005). The metaphysics of apes: Negotiating the human-animal boundary. Cambridge, United Kingdom: Cambridge University Press.

Crist, E. (2000). Images of animals: Anthropomorphism and animal mind. Philadelphia: Temple University Press.

De Waal, F. (2001). The ape and the sushi master: Cultural reflections by a primatologist. London: Basic Books.

De Waal, F., \& Tyack, P. (Eds.). (2003). Animal social complexity: Intelligence, culture, and individualised societies. Cambridge, MA: Harvard University Press.

Fox, R. (1989). The search for society: Quest for a bio-social science and morality. New Brunswick: Rutgers University Press.

Fudge, E. (2002). Animal. London: Reaktion Books.

Haraway, D. (1984). Primatology is politics by other means. In Proceedings of the biennial meeting of the Philosophy of Science Association, USA, 2, 489-524.

- (1990). Primate visions: Gender, race, and nature in the world of modern science. London: Routledge.

- (2003). The companion species manifesto: Dogs, people, and significant otherness. Chicago: Prickly Paradigm Press.

- (2007). When species meet (posthumanities). Minneapolis: University of Minnesota Press.

Hubbard, R. (1990). The politics of women's biology. New Brunswick, NJ: Rutgers University Press.

Irvine, L. (2004). If you tame me: Understanding our connections with animals. Philadelphia: Temple University Press.

Jackson, S., \& Rees, A. (2007). The appalling appeal of nature: The popular influence of evolutionary psychology as a problem for sociology. Sociology, 41(5), 917-930. 
Keller, E. F. (1985). Reflections on gender and science. New Haven: Yale University Press.

Latour, B. (1993). We have never been modern. Harlow: Pearson.

(2000). A well-articulated primatology: Reflections of a fellow traveller. In S. Strum \&

L. Fedigan (Eds.). Primate encounters. Chicago: University of Chicago Press.

- (2004). The politics of nature: How to bring the sciences into democracy. Cambridge, MA: Harvard University Press.

Latour, B., \& Woolgar, S. (1986). Laboratory life: The construction of scientific facts. Princeton, NJ: Princeton University Press. (Original work published 1979)

McFarland, D. (2006). Oxford dictionary of animal behaviour. Oxford: Oxford University Press.

McGrew, W. (1998). Culture in nonhuman primates? Annual Review of Anthropology, 27, 301-328.

- (2003). Ten dispatches from the chimpanzee culture wars. In F. De Waal \& P. Tyack (Eds.). Animal social complexity. Cambridge, MA: Harvard University Press.

Mead, G. H. (1967). Mind, self, and society. Chicago: University of Chicago Press. (Original work published 1934)

Michael, M. (2000). Reconnecting culture, technology and nature: From society to heterogeneity. London: Routledge.

Mitchell, R. (1999). History of great ape psychology: Scientific and popular conceptions of the psychology of great apes from the 1790s to the 1970s: Déjà vu all over again. Primate Report 53. Gottingen: German Primate Centre (DPZ).

Myers, O. (2003). No longer the lonely species: A post-Mead perspective on animals and sociology. International Journal of Sociology and Social Policy, 23(3), 46-68.

Nagel, T. (1974). What is it like to be a bat? Philosophical Review, 83(4), 435-450.

Nimmo, R. (2011). The making of the human: Anthropocentrism in modern social thought. In R. Boddice (Ed.). Anthropocentrism: Humans, animals, environments (pp. 59-79). Leiden: Brill. Plumwood, V. (1993). Feminism and the mastery of nature. London: Routledge.

Rees, A. (2006). A place that answers questions: Primatological field sites and the making of authentic observations. Studies in History and Philosophy of Biological and Biomedical Sciences, 37(2), 311-333.

. (2007). Reflections on the field: Primatology, popular science and the politics of personhood. Social Studies of Science, 37(6), 881-907.

Sanders, C. (1999). Understanding dogs: Living and working with canine companions. Philadelphia: Temple University Press.

- (2006). The sociology of human-animal interaction and relationships. H-Animal Net. Retrieved October 15, 2010, from http://www.h-net.org/ animal/ruminations_sanders.html.

Schutz, A. (1967). The phenomenology of the social world. Evanston, IL: Northwestern University Press.

Shapiro, K., \& Copeland, M. (2005). Toward a critical theory of animal issues in fiction. Society \& Animals, 13(4), 343-346.

Shapiro, K., \& DeMello, M. (2010). The state of human-animal studies. Society \& Animals, 18(3), 307-318.

Strum, S., \& Fedigan, L. (2000). Changing views of primate society. In S. Strum \& L. Fedigan (Eds.). Primate encounters: Models of science, gender, and society (pp. 3-49). Chicago: University of Chicago Press.

Weber, M. (1964). Max Weber: Theory of social and economic organisation. New York: Free Press.

- (1968). Economy and society: An outline of interpretive sociology. New York: Bedminster Press. (Original work published 1922)

Whiten, A. (2000). Primate culture and social learning. Cognitive Science, 24(3), 477-508.

Williams, R. (1983). Culture and society: 1780-1950. New York: Columbia University Press. 
Williamson, E., \& Feistner, A. (2011). Habituating primates: Processes, techniques, variables and ethics. In J. Setchell \& D. Curtis (Eds.). Field and laboratory methods in primatology. Cambridge, United Kingdom, Cambridge University Press.

Wilson, E. (1975). Sociobiology: The new synthesis. Cambridge, MA: Harvard University Press.

Winch, P. (2007). The idea of a social science and its relation to philosophy. London: Routledge. (Original work published 1958)

Wolfe, C. (2009). Human, all too human: Animal studies and the humanities. Publications of the modern language association of America, 124(2), 564-575.

. (2010). What is posthumanism? Minneapolis: University of Minnesota Press.

Wrangham, R., De Waal, F., Heltne, P., \& McGrew, W. (Eds.). (1994). Chimpanzee cultures. Cambridge, MA: Harvard University Press. 